\title{
AN ANALYSIS OF OPTIMAL DEVOLVED GOVERNMENT SIZE FOR GROWTH: ARMEY CURVE IN KENYA
}

Naftaly Mose ${ }^{1}$

\section{Introduction}

The recent global initiative towards federalized spending has been gradually justified on the basis that decentralization of resources to sub-national governments level are likely to deliver greater efficiency in the delivery of public goods and services and consequently stimulate economic activities at devolved units (Martinez-Vasquez and McNab 2006). The devolution trend in unindustrialized nations is reinforced by the International Monetary Fund (IMF) and World Bank (WB), which considers expenditure decentralization as a key pillar of its economic growth and poverty eradication strategy (World Bank 20I6). But, attention to expenditure transfer has been mainly inspired by local political reasons (Mwiathi 20I7). Like the case of Kenya in $2007 / 2008$. The $2007 / 2008$ post-election violence saw the introduction of the new governance system, which entrenched devolved systems (GoK 2010). In a number of nations including Kenya, a devolved system of governance refers to devolution. Essentially devolution is one form of fiscal decentralization. However, devolution is more extensive and includes transfer of both economic and political powers from central government to devolved units (Ezcurra and Rodríguez-Pose 2010).

There are two competing views relating to the impact of government size on economic growth. According to one group of economists, a larger government size is likely to be harmful to economic growth due to the inefficiencies inherent in government. According to Barro et al. (2003) a

I Department of Pure Economics, School of Economics, University of Eldoret, Eldoret, Kenya. E-mail: ngmoce@uoeld.ac.ke 
large government size may have a negative impact on economic growth due to government inefficiencies such as excess burden of taxation, distortion of the incentive systems and interventions to markets. The other group of economists is of the view that a larger size of government is likely to accelerate economic growth. The government has authority to remove and regulate negative externalities (Munene 20I5). Thus, the government plays an important role in removing interest conflicts between the private and public sector (Mose et al. 2019).

From previous empirical literature, a number of studies that examined the different channels through which devolution influences growth produced various outcomes (World Bank 20I6). The variations in the optimal sizes of governments are a result of the differences in the sizes of the economies, levels of development and government policies in the respective countries. In conclusion all these findings indicate that excessively large government sizes over and beyond the optimal sizes would retard economic growth (Munene 20I5). In economic theory, expenditure decentralization can stimulate economic activities and initiate further growth in governance and the political process. Further, from previous studies fiscal delegation is expected to positively grow county economic growth (Yemek 2005). Alternatively, devolution can slow economic growth if it is not complemented with improved governance and transparency at lower tier government (Martinez-Vasquez and McNab 2006).

The proportion of fiscal decentralization has conventionally been higher in federal states, for instance USA, Ethiopia, Canada, Ghana and South Africa (Yemek 2005; SID 20I7). The 20I4 share of devolved budgets in Kenya (20 percent of aggregate budget), resembled the same level of spending in the region; for instance, in Tanzania and Uganda devolved expenditure by aggregate budget accounted for 22 and 20 per cent, respectively; while in Ethiopia it was about 46 per cent of aggregate budget (GoK 20I5; SID 20I7).

\section{Table 1: Government Expenditure share on Economic growth}

\begin{tabular}{lllllll}
\hline YEAR & $\mathbf{2 0 1 2}$ & $\mathbf{2 0 1 3}$ & $\mathbf{2 0 1 4}$ & $\mathbf{2 0 1 5}$ & $\mathbf{2 0 1 6}$ & $\mathbf{2 0 1 7}$ \\
\hline Real GDP growth rate - (\%) & 4.6 & 5.9 & 5.4 & 5.7 & 5.9 & 4.9 \\
National Expenditure - (\% GDP) & 23.7 & 23.7 & 25.9 & 26.6 & 25.3 & 24.6 \\
County Expenditure - (\% GDP) & 1.0 & 4.3 & 5.4 & 5.4 & 5.3 & 5.3 \\
\hline
\end{tabular}

Source: OCOB (20I8). 
From Table I, it is clear that the share of county and national government expenditure on economic growth has been rising, both local and state levels. However, the growth of government expenditure is double digit while economic growth is expanding at a single digit (GoK 20I7; OCOB 20I8). The increasing wage bill accounts for the rapid growth in the county and state budgets over the years (OCOB 20I8). The trends in this Table I reveal a widening gap between public expenditure, county and national, and economic growth performance and therefore a concern that this study is interested in.

Expenditure devolution measured as a share of county spending to GDP increased from 4.3 per cent in 2013 to 5.4 per cent by 2017 . However, economic growth declined from 5.9 per cent by 2013 to 4.9 per cent in 2017. This was mainly attributed to poor governance, election period, poor weather conditions, unfavorable policy conditions and overall diminishing economic performance (KIPPRA 20I6; GoK 20I8). Despite an increase in devolved budget, county economic growth has remained volatile in Kenyan counties.

Even with the devolved expenditure growth, Kenya's Gross Domestic Product (GDP) growth has been lower than yearly estimated targets, widening income and county disparities and increase in poverty rate over the years. Fluctuating economic growth adversely affects income expansion, regional and income equality growth, poverty reduction and overall Kenya's macroeconomic stability (KIPPRA 20I6; GoK 20I9). This advances the reservation on if devolved public expenditure is an effective fiscal policy tool for achieving county and national economic growth, planning, equality growth, stabilization, distribution and poverty eradication in Kenya. And if so, how can it be used to address macroeconomic problems in Kenyan Counties.

\section{Problem Statement}

The causes of many of the disparities in economic growth over time are not well understood. In particular, the optimal size of county government expenditure on economic growth has not been investigated exhaustively. Despite the widespread government strategies to foster economic expansion, increase in county government expenditure has tended to grow faster than that of GCP. The trends in the Table I reveal a widening gap between the county government size and county economic growth and therefore a concern that this study is interested in. Therefore, there is a need to investigate the optimal government size for policy recommendations. 


\section{Objective}

The objective is to determine the optimum size of county government spending on county economic growth in Kenya.

\section{Research Hypothesis}

The optimal size of county government spending on county economic growth does not exist in Kenya.

\section{Literature Review: The Optimal Government Size}

Armey (I995) and Scully (2003) did theoretical and empirical research and popularized the existence of an optimal size of government as depicted by an inverted U-curve. As government continues to grow as a share of the economy, expenditures are channelled into less productive (and later counterproductive) activities, causing growth to diminish and eventually decline (Vedder and Gallaway I998; Leach 2002; Barro and Sala-i 2003; Mose et al. 20I9).

\section{Figure 1: Armey Curve}

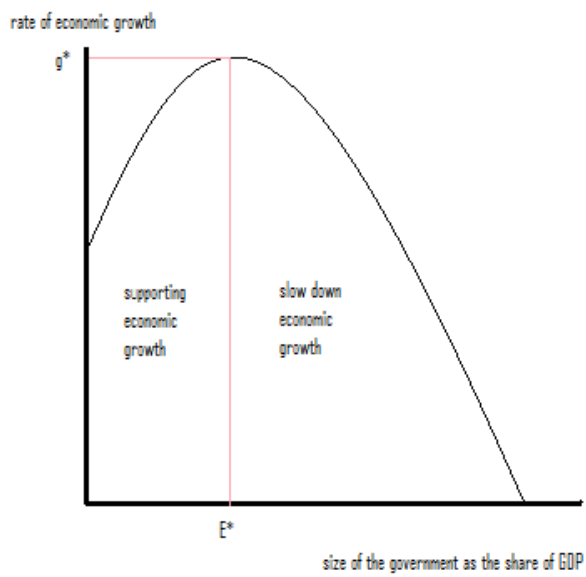

Notes: ${ }^{g g}$ - Real Gross County Product (Proxy for Economic Growth); E E - Equilibrium; CGE CGE _ County Government Expenditure (Proxy for Government Size); ${ }^{\mathrm{TT}}$ - Time variable. Source: Armey (1995); Leach (2002); Scully (2003). 
Explanations for this trend can be found in the decrease of private investments due to the 'crowding-out' effect, higher tax rates and less free market. Additionally, the Armey Curve indicates an optimal size of the government $\mathrm{E}^{*}$, where maximum economic growth is reached. At this point, an increasing amount of public expenditure leads to a decrease of economic growth. This point differs country by country and may rely on economic factors like openness of the economy as well as social factors like population size (Armey I995; Leach 2002).

The Armey Curve can be expressed in a simple quadratic form (I), as follows:

$$
\left(g_{i, t}\right)=\alpha+\beta(C G E)_{i t}+\delta(C G E)_{i t}^{2}+\gamma T
$$

The positive sign of the linear term, CGE, is designed to show the beneficial effects of government spending on economic expansion, while the negative sign of the squared term means the variable measures any adverse effects associated with increased government size. Since the squared term increases in value faster than the linear term, the presence of negative effects from government spending eventually will outweigh the positive effect, producing a downward-sloping portion of the Armey Curve (Armey I995; Leach 2002; Lazaruset al. 20I7). To control the factors unrelated to government spending, Vedder and Gallaway (I998) introduced the time variable (T). Therefore, the faster and greater the expenditure increases, the greater the probability of diminishing returns and ineffective use.

\section{The Armey Curve Quadratic Equation}

In order to test the relationship between County Government Expenditures (CGE) and economic growth that is theoretically characterized by the inverted U curve, this study uses a simple quadratic equation (2) following Armey (I995), Vedder and Gallaway (I998), Facchini and Melki (2013), and Lazaruset al. (20I7).

$$
\left(G C P_{i, t}\right)=a+b(C G E)_{i t}+c(C G E)^{2}{ }_{i t}
$$

The (CGE) which guarantees the optimal level of county economic growth (GCP) is derived by taking the first derivative of the equation (2) in respect to CGE and then equated to zero. 


$$
\begin{aligned}
& \frac{\partial G C P}{\partial C G E}=b+2(c) C G E_{i, t} \\
& \frac{\partial G C P}{\partial C G E}=b+2(c) C G E_{i, t}
\end{aligned}
$$

(3)

Equating equation (3) to zero gives the optimum government size percentage.

$$
C G E=-\frac{b}{2 c}
$$

(4)

\section{The Scully Model}

Scully (2003) and Scully (2008) developed a model that estimates the share of county government spending (or general tax rate) that maximizes real economic growth. According to the Scully model, both the public as well as private sectors contribute to the gross domestic product in counties. The public sector provides goods and services which are financed with tax collections from the population. This becomes the public sector spending. On the other hand, the private people give taxes to the government and a fraction of the rest of their income is saved which in turn is used to produce goods and services. The fraction of the income of the private people given to the county government is given by:

$$
\frac{T}{Y}=\tau
$$

Where $\mathrm{T}$ is the total taxes and $\tau$ is the associated tax rate and $\mathrm{Y}$ is the GDP. Or in other words, $\tau$ is the share of the county public sector in GDP. The share of the private sector in GDP is "I- $\tau$ ". (I- $\tau$ ) is the share of the income of the people left with them after taxation which leads to the production of goods and services. The functional form of this relationship is given by the following Cobb-Douglas production form as:

$$
\begin{aligned}
& Y_{i t}=\gamma\left(\frac{G}{Y}\right)^{\alpha}(1-\tau)^{\beta} \\
& Y_{i t}=\gamma\left(\frac{G}{Y}\right)^{\alpha}(1-\tau)^{\beta}
\end{aligned}
$$


${ }^{\alpha \boldsymbol{\alpha}}$ and ${ }^{\boldsymbol{\beta} \boldsymbol{\beta}}$ are the shares of the public and private sectors respectively. Equation (5) is a nonlinear production. Y is GDP and G is county government expenditure. ' $\tau$ ' shows the ratio of tax to GDP and ' $\gamma$ ' shows total factor productivity. The log transformation of equations (5) is given by:

$$
\ln Y_{i t}=\ln \gamma+\alpha \ln \left(\frac{G}{Y}\right)+\beta \ln (1-\tau)
$$

This is simplified as follows:

$$
\alpha\left(\frac{Y}{G}\right)\left(\frac{1}{Y}\right)=\alpha G^{\beta-1}
$$

Now taking second derivative with respect to $G$, thus get:

$$
\begin{aligned}
& \frac{\partial^{2} \ln Y}{\partial \mathrm{G}^{2}}=-\alpha \mathrm{G}^{-2} \\
& \frac{\partial^{2} \ln Y}{\partial \mathrm{G}^{2}}=-\alpha \mathrm{G}^{-2}
\end{aligned}
$$

This exercise shows that the value of the first derivative is positive while the second derivative is negative as is shown by the negative sign of the second derivative. This shows that public expenditure affects growth positively, but the magnitude of this effect decreases over the time i.e it affects economic growth at a decreasing rate afterward. This results in a non-linear relationship between expenditure and growth (Scully 2003; Husnain, Khan, Haq Padda, Akram and Haider 20II).

\section{The Empirical Literature}

Lazaruset al. (20I7) investigated the optimal expenditure from I970 to 20I4 using panel ARDL. The study established that the optimum government sizes were $36.61 \%, 15.61 \%$, and $23.13 \%$ of the real GDP for the 27 OECD, 50 African, and 77 African and OECD countries, respectively.

Munene (20I5) used an OLS and Armey curve quadratic equation to analyse the optimal size of expenditure and economic growth in Kenya in the period I963-2012. The major finding of this study is that growth maximizing expenditure as a percent of GDP was estimated to be $23 \%$.

Shumaila and Abdul (20I4) estimated optimal government size for growth in Pakistan by using Scully (2008) methodology for the period from 
I973 to 20I2. The optimal size of the government size or equivalently the optimal size of the public spending was found to be around I7 percent of the GDP. The actual size of the spending was I8 per cent.

Olaleye et al. (20I4) used an OLS and Armey curve quadratic equation to analyse the effect of government expenditure and economic growth in Nigeria in the period I983-2012. The study concluded that Nigeria optimum government expenditure size is II\% of the GDP.

Facchini and Melki (2013) analysed the presence of an Armey curve in France (I87I - 2008). The study used the OLS linear model to estimate. The findings confirmed the Armey curve and the optimal government size for France was $30 \%$ of GDP.

Husnain (20II) estimated the optimal government size in Pakistan following the methodology of Scully (2008). The findings have shown that the threshold level of the government expenditure is $2 \mathrm{I} .48$ percent of GDP, which is lower than the current size.

Scully (2008) argues that the optimal tax rate or equivalently the optimal size of the government ranges from ig to 23 percent. This study also affirmed that the optimal tax rate for New Zealand on average is I9.7 percent of the GDP over the period I927-I994.

\section{Methodology}

This study employed quantitative research design so as to capture the trend of county economic growth and government expenditure in Kenya. This was carried out in the period 20I3 - 20I7 using annual series secondary data for 47 counties and panel ARDL technique, resulting in 235 county-year observations. This study was carried out in Kenya. This is because in the study period, there has been a significant transfer of funds to 47 county governments by the national government in order to address disparities in country growth.

The data was from previous publications which could only be sourced from secondary sources. The study utilized annual data from Statistical Abstracts, Economic Surveys, Gross County Product Report and County Budget Implementation Review Reports. 


\section{Panel Data Analysis Techniques}

Building on previous studies (Facchini and Melki 2013; Mose et al. 2019), a simple growth panel model was formulated from equation (7):

$$
\begin{aligned}
& \operatorname{lngrgd} p_{i, t}=\beta \ln X_{i, t}+\gamma \ln G_{i, t}+\mu_{i}+v_{t}+\varepsilon_{i, t} \\
& \ln Y_{i, t}=\beta \ln X_{i, t-1}+\gamma \ln G_{i, t-1}+\mu_{i}+v_{t}+\varepsilon_{i, t} \\
& \ln Y_{i, t}=\beta \ln X_{i, t-1}+\gamma \ln G_{i, t-1}+\mu_{i}+v_{t}+\varepsilon_{i, t}
\end{aligned}
$$

Where, $\ln Y i, t$ - the dependent variable-County economic growth. expenditure.

$\ln X i, t-1$ - set of explanatory variables apart from devolved county

$\ln G i, t-1$ - the county devolved government expenditure variables.

$\beta$ and $\gamma$ - are parameters to be estimated.

$\mu i$ - county fixed effects. $v t$ - time fixed effects. $\varepsilon i, t-$ the error term and the subscripts $i$ and $t$ represent county and time period respectively.

To achieve this objective, this study followed Scully (2008) and ARDL model that explains the level of government size $(G)$ in a county's economy and the corresponding level of economic growth. The ARDL model is applicable irrespective of whether the underlying variables are I(O) or I(I) and applicable for small sample size estimation (Narayan and Smyth 2005).

Thus, equation (7) was reformulated as a panel ARDL model, to determine the underlying relationship between dependent and independent variables, to obtain models (8) below:

$$
\Delta \ln Y_{i, t}=\sum_{i=1}^{k} \beta \Delta \ln X_{i, t-1}+\sum_{i=1}^{k} \gamma \Delta \ln G_{i, t-1}+\mu_{i}+v_{t}+\varepsilon_{i, t}
$$

Now to find the optimal level of government size, this study follows Scully (2008) and Heerden (2008) to impose the restriction of a balanced budget of the counties, that is $(G=T)$. So to impose this balanced budget restriction the tax rate is given by:

$$
\frac{G}{Y}=\tau
$$


${ }^{\tau} \tau$ now is called the anticipated tax rate, where $G$ is government spending and $\mathrm{Y}$ is GDP. Or in other words, $\tau$ is the share of the county public sector in GDP. The share of the private sector in GDP is "I- $\tau$ ". (I- $\tau$ ) is the share of the income of the people left with them after taxation which leads to the production of goods and services. The functional form of this relationship is given by the following Cobb-Douglas production form (9) as:

$$
\begin{aligned}
& Y_{i t}=\gamma\left(\frac{G}{Y}\right)^{\alpha}(1-\tau)^{\beta} \\
& Y_{i t}=\gamma\left(\frac{G}{Y}\right)^{\alpha}(1-\tau)^{\beta}
\end{aligned}
$$

(9)

${ }^{\alpha a}$ and ${ }^{\beta \beta}$ are the shares of the public and private sectors respectively. Equation (9) is a nonlinear production. Y is GCP and G is county government expenditure. ' $\tau$ ' shows the ratio of tax to GCP and ' $\gamma$ ' shows total factor productivity. The log transformation of equation (9) is given by::

$$
\ln Y_{i t}=\ln \gamma+\alpha \ln \left(\frac{G}{Y}\right)+\beta \ln (1-\tau)
$$

$$
\begin{gathered}
\text { Now substitute ' } \frac{G}{Y}=\tau \quad \frac{G}{Y}=\tau, \text { into equation (IO), thus get: } \\
\ln Y_{i t}=\ln \gamma+\alpha \ln \tau+\beta \ln (1-\tau)
\end{gathered}
$$

So to find the growth maximizing level of government size, this study differentiates equation (II) w.r.t ' $\tau$ '. After differentiation, then:

$$
\begin{gathered}
\frac{\partial \ln Y}{\partial \tau}=\frac{\partial \alpha \ln \tau}{\partial \tau}-\frac{\partial \beta \ln (1-\tau)}{\partial \tau}=0 \\
\frac{\alpha}{\tau}-\frac{\beta}{1-\tau}=0
\end{gathered}
$$

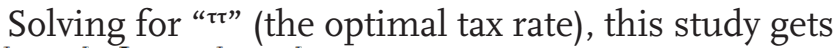
$\beta \tau=\alpha(1-\tau) \beta \tau=\alpha(1-\tau)$, and finally: 


$$
\tau^{*}=\alpha /(\alpha+\beta)
$$

In order to provide intuitive interpretation of the findings obtained from this study, several post estimation panel diagnostic tests were conducted.

\section{Results}

The panel ARDL regression results are reported in Table 2 given below:

Table 2: Optimal Devolved Expenditure Regression Result (SBC - 1, 0, 0)

\begin{tabular}{|c|c|c|c|c|}
\hline Variable & Coefficient & Margin of Error & t- Statistics & Value $\mathrm{P}$ \\
\hline $\ln y(-1)$ & $0.842831^{* * *}$ & 0.033217 & 25.37367 & 0.0000 \\
\hline $\ln \tau$ & $0.152954^{* * *}$ & 0.032901 & 4.648914 & 0.0000 \\
\hline $\ln (1-\tau)$ & $1.422697^{* *}$ & 0.601285 & 2.366096 & 0.0188 \\
\hline Cons & $0.995023 * * *$ & 0.171124 & 5.814626 & 0.0000 \\
\hline Test LM & \multicolumn{2}{|c|}{$F=0.988767$} & \multicolumn{2}{|c|}{ Prob $>F=0.4147$} \\
\hline Test Breusch - Pagan & \multicolumn{2}{|c|}{$\mathrm{F}=8.876056 * * *$} & \multicolumn{2}{|c|}{ Prob $>F=0.0000$} \\
\hline Test Pesaran CD & \multicolumn{2}{|c|}{$z=-1.156541$} & \multicolumn{2}{|c|}{$\operatorname{Pr}=0.2475$} \\
\hline Test Ramsey-Reset & \multicolumn{2}{|c|}{$F=1.818203$} & \multicolumn{2}{|c|}{$\operatorname{Pr}=0.1789$} \\
\hline Test Goodness of Fit & \multicolumn{2}{|c|}{ F statistics $=226.6525^{* * *}$} & \multicolumn{2}{|c|}{$P$-value $(F)=0.0000$} \\
\hline Test Goodness of Fit & \multicolumn{2}{|c|}{$\mathrm{R}^{2}=0.747241$} & \multicolumn{2}{|c|}{$\mathrm{R} 2$ Ajustado $=0.743944$} \\
\hline
\end{tabular}

Notes: $* * *$ significant at $1 \%, * *$ significant at $5 \%$, all the absolute values of the variables are expressed in natural log. $\ln Y \ln Y_{i t} \ln Y_{i t}$ - County real GCP (economic growth), $\ln \tau \ln \tau$-devolved expenditure (recurrent+capital), $1-\tau 1-\tau$-share of the private sector in GCP.

The above results of the equation for the optimal size of the government show that all the variables have carried out significant coefficients as shown by high "t" statistics: 


$$
\begin{aligned}
& \ln Y_{i t}=0.995023+0.152954 \ln \tau+1.422697 \ln (1-\tau) \\
& \ln Y_{i t}=0.995023+0.152954 \ln \tau+1.422697 \ln (1-\tau)
\end{aligned}
$$

To calculate the optimal county government size, this study uses equation (II). So substitute the values of " $\alpha$ " and " $\beta$ " from the above in equation (I3), then getting:

$$
\tau=\frac{0.152954}{0.152954+1.422697} * 100=9.7
$$

The optimal size of the devolved government size (both capital and recurrent) is found to be around 9.7 percent of the GCP as is shown by the above empirical analysis against actual 5.4 percent of GCP in 20I7. This reflects a reduction in public spending over the optimal target. On the other hand, the actual average size of the government spending is 5.4 percent for 20I5-20I7 (KIPPRA 20I6; SID 20I7). The optimum government size was low considering counties only receive $\mathrm{I} 5 \%$ of total revenue from the national government. This finding is very much interesting since it highlights that the current size of county government in Kenya is below the optimum level or size and there is still scope of the increase in devolved government spending to the GCP ratio in Kenya. The share of devolved funds traditionally is higher in federal countries, with Nigeria, Brazil and Ethiopia (World Bank 2OI4; OCOB 2OI4; GoK 2OI6). The finding of this study fits into the Obben (2013) study, which found 7.4\% of GDP for OECD countries, including Kenya. In contrast, Legge (20I5) did not find any optimal government size in the countries (DCs and LDCs) studied.

From the result in Table 2 above, cross-sectional dependence and autocorrelation were not a problem with this study. However, heteroscedasticity was a problem, but the study used panel robust standard error to correct it. Also, the adjusted $\mathrm{R}^{2}$ was 0.74 implying that 74 percent of the variation of the dependent variable is explained by the explanatory variables in the model. This indicated that the overall goodness of fit was satisfactory. 


\section{Conclusion}

The result for the objective of this study was to estimate the optimum size of devolved county government. According to the estimation results of the Scully model, optimum government sizes were $9.7 \%$ of the GCP. The actual average government size was $5.4 \%$ of the GCP for the devolved for Kenyan counties during the period of review. The optimum county government size was above the actual government in the panel regression model. The low level of devolved government size in counties reflects the low level of economic development in Kenya. This study concludes that there is an inverted $\mathrm{U}$ shape curve in the panel regression models. Also, devolved expenditure had a significant positive effect. Hence, suggesting that the productivity of devolved spending exceeds the deadweight loss associated with high taxes. As a result, county spending augments the aggregate demand, which stimulates an increased output depending on expenditure multipliers.

\section{Recommendations}

Based on the results above, it is clear that the significant effects of the government expenditure on economic growth are not independent from government size. Verifying their relationship as a U-shaped curve, implementation of the following recommendations for 47 counties becomes worthy of attention: Fixing the share of government expenditures in counties with the optimum government size ( $9.7 \%$ of GCP), this recommendation can guarantee high and stable county economic growth. The low level of government size in counties reflects the low level of economic growth in Kenya, hence this study recommends devolved expenditure to be increased by county government from $5.4 \%$ to $9.7 \%$ of GCP. Also, in comparison to other countries, Kenyan share of county level expenditure, $20 \%$ of total expenditure, closely mirrors the levels in the region. However, for Ethiopia, it accounts for 46.0 per cent of total expenditure, probably because it has been implementing devolution for longer than Kenya. Thus, Kenya has room to improve budget allocation to be in the same league with her peers like Ethiopia. However, an increase in spending that is not matched by an increase in revenues leads to a budget deficit that needs to be financed. If the deficit is financed by issuing domestic debt, it can have negative consequences for domestic interest rates, which crowds out private spending before retarding county growth. 
In future studies, macroeconomic analysis should be extended to include a more detailed disaggregation of county government expenditures by functions. Such a desegregation would allow extension of the analysis and distinguish between the optimal size of devolved recurrent spending, capital expenditure and human expenditure on county economic growth.

\section{References}

Armey, Dick. I995. The Freedom Revolution. Washington D.C.: Regnery Publishing.

Barro, Roberto and Sala-i-Martin, Xavier. 2003. Economic Growth. 2nd ed. Cambridge: MIT press.

Ezcurra, Roberto and Rodríguez-Pose, Andrés. 2010. "Is Fiscal Decentralization Harmful for Economic Growth? Evidence from the OECD Countries". SERC Discussion Paper 51. Londres: London School of Economics.

Facchini, François and Melki, Mickaël. 20I3. "Efficient Government Size: France in the 2oth century". European Journal of Political Economy 3I: I-I4.

GOK (Government of Kenya). 2004- 2019. Economic surveys. Nairobi: Kenya National Bureau of Statistics.

Heerden, Yolande Van and Schoeman, Nieck J. 2008. "Finding the Optimal level of Taxes in South Africa: A Balanced Budget Approach”. Working Paper. Pretoria: University of Pretoria.

Husnain, M. I. 20II. Is the Size of Government Optimal in Pakistan: A Time Series Analysis, I975-2008. Journal of Economics Q Economic Education Research I2, no. 2.

Husnain, M. I., Khan, M., Haq Padda, I., Akram, N. and Haider, A. 2 oII. "Public Spending, FDI and Economic Growth: A Time Series Analysis for Pakistan (I975-2008)". International Research Journal of Finance and Economics 6I: 2I-27.

Institute of Economic Affairs (IEA). 20I0. "Devolution in Kenya, Prospects, challenges and the future". IEA Research paper, series no.24.

Kenya Institute for Public Policy Research and Analysis (KIPPRA). 2016. Kenya Economic Report: Fiscal Decentralization in Support of Devolution, Nairobi: The Kenya Institute for Public Policy Research and Analysis. 
Kenya National Bureau of Statistics (KNBS). 20I9. Gross County Product Report 2019. Nairobi.

Leach, G. 2002. "We are going the Wrong Way-Tax and Spending Fiscal Policy". IoD Policy Paper, London.

Legge, Stefan. 2015. Government Size and Economic Growth: The Role of Country Diversity. http://www.spring2015-2015201030I7pdf.

Martinez-Vazquez, Jorge and Robert M. McNab. 2006. "Fiscal Decentralization, Macro - stability and Growth”. Working Paper, no. 05-06: 25-49.

Mose, Naftaly, Lawrence Kibet and Simon Kiprop. 2019. "The effect of county government expenditure on Gross County Product in Kenya: A panel data analysis". African Journal of Business Management I3, no. I3: 428-437.

Mwiathi, Peter Silas. 20I7. Effects of Fiscal Decentralization on Poverty Reduction Outcomes, Income Inequality and Human Development in Kenya. PhD thesis. Kenyatta University..

Narayan, Paresh K. and Smyth, Russell. 2005. "The residential demand for electricity in Australia: an application of the bounds testing approach to cointegration". Energy Policy 33: 457-464.

Nijenhuis, Karin. 2003. "Does Decentralization Serve Everyone? The Struggle for Power in Malian Village". The European Journal of Development Research I5, no. 2: 67-92.

Obben, James. 2013. "Aspects of the Government Size-Economic Growth Rate Nexus in the OECD: I973-20II". Discussion Paper 13.04: I-3I.

Office of the Controller of Budget (OCOB). 2013-2019. Annual County Governments Budget Implementation Review Report. Nairobi: Government Printer.

Olaleye, Samuel, Edun Femi, Hassan T. Bello and Shakirundeen B. Taiwo. 20I4. "Government Expenditure and Economic Growth: Armey Curve in Nigeria”. The Romanian Economic Journal I7, no. 51: 47-66.

Scully, Gerald. 2003. "Optimal taxation, economic growth and income inequality”. Public Choice II5, no. 3/4: 299-3I2.

. 2008. "Optimal Taxation, Economic Growth and Income Inequality in the United States”. National Center for Policy Analysis, Policy Report no. 3I6: I-I2.

Shumaila, Zareen and Qayyum Abdul. 20I4. "An Analysis of Optimal Government Size for Growth: A Case Study of Pakistan". Munich Personal RePEc Archive, paper No. 58989: I-I2. 
Society for International Development (SID). 20I7. "Taxation and fiscal decentralisation in Kenya; a case study of Kwale, Kiambu and Kisumu Counties". Working Paper No.3.

Vedder, Richard K. and Gallaway, Lowell E. I998. Government Size and Economic Growth. Washington: Ohio University press.

Lazarus, Wanjuu Zungee; Khobai, Hlalefang; Le Roux, Pierre. 20I7. Government Size and Economic Growth in Africa and the OECD. International Journal of Economics and Financial Issues 7, no. 4: 628-637.

World Bank. 20I4. Decision Time: Spend More or Spend Smart? Decision Time: Spend More or Spend Smart? Working paper, No. 9402I, Nairobi.

. 20I6. Kenya Country Economic Memorandum: From Economic Growth to Jobs and Shared Prosperity. Working Paper, No. I03822, Nairobi.

Yemek, Etienne. 2005. "Understanding Fiscal Decentralisation in South Africa". Institute for Democracy in South Africa (IDASA) paper: I-25.

\section{ABSTRACT}

This study, assuming a balanced budget, attempts to estimate the optimal size of devolved government expenditure in 47 Kenyan counties using the panel ARDL regression and Scully (2008) model for the period 20I4-20I8. The estimation model examined Armey's idea of a quadratic curve that explains the level of government expenditure in an economy and the corresponding level of economic growth. The panel ARDL series analysis reveals that devolved government size is optimized when county expenditures stand at 9.7\% of GCP (Gross County Product). The estimated threshold size is higher than the current size of county government in Kenya. The low level of devolved government size in counties reflects the low level of economic activities in Counties. This study therefore recommends that county governments should increase its spending budget on infrastructure, social and economic activities to $9.7 \%$ of GCP to stimulate overall county economic growth.

\section{KEYWORDS}

County; Optimal; Devolved; Expenditure; GCP; Balanced Budget. 